\title{
Morphology of the corpus callosum and schizophrenia: A case-control study in Kashan, Iran
}

\author{
Afshin Ahmadvand ${ }^{1}$, Shahab Bagherzadeh Shahidi ${ }^{2}$, Hamidreza Talari ${ }^{3}$, Fatemeh Sadat Ghoreishi ${ }^{3}$, Gholam \\ Abbas Mousavi ${ }^{4}$
}

${ }^{1}$ M.D., Psychiatrist, Associate Professor, Department of Psychiatry, Kashan University of Medical Sciences, Kashan, Iran

${ }^{2}$ M.D., Psychiatrist, Faculty Member, Department of Psychiatry, Kashan University of Medical Sciences, Kashan, Iran

${ }^{3}$ M.D., Psychiatrist, Assistant Professor, Department of Psychiatry, Kashan University of Medical Sciences, Kashan, Iran

${ }^{4}$ M.S., Faculty of Health, Department of Statistics and Public Health, Kashan University of Medical Sciences, Kashan, Iran

\section{Type of article: Original}

\begin{abstract}
Background: Corpus Callosum (CC) plays a significant role in hemispheric communication and in lateralized brain function and behaviors. Structural abnormalities in the corpus callosum of schizophrenic patients were reported. However, previous studies regarding the relationship between morphology of CC in patients with schizophrenia and healthy people are controversial.

Objective: To evaluate the morphological differences of the $\mathrm{CC}$ between patients with chronic schizophrenia and healthy people and to examine the relationship between the characteristics of the $\mathrm{CC}$ and schizophrenia severity.

Methods: This cross-sectional study was conducted on 63 patients with chronic schizophrenia (the case group) referred to Kargarnezhad Psychiatric Hospital in Kashan, Iran, and 63 healthy people (the control group) between January 2013 and December 2014. All participants underwent brain magnetic resonance imaging. Shape, anteroposterior length, and area of the CC were measured and compared in both groups. The severity of the symptoms occurring in patients with schizophrenia was evaluated using the positive and negative syndrome scale. In this study, we employed Chi-square test, t-test, Pearson product-moment correlation coefficient test, bivariate analysis of variance and logistic regression were used to test the association between different variables using SPSS software version 20.

Results: Results showed that the most common shape of the CC in each group was splenial bulbosity. The length and area of the $\mathrm{CC}$ in patients with schizophrenia were less than those of the control group and were greater in men compared with women in both groups. Although there was a significant difference in the surface area of the $\mathrm{CC}$ between the schizophrenic and control groups $(\mathrm{p}<0.001)$, no significant difference was seen regarding the anteroposterior length of $\mathrm{CC}(\mathrm{p}=0.75)$. Moreover, a significant correlation was found between the surface area and anteroposterior length of the $\mathrm{CC}(\mathrm{p}<0.001$ and $\mathrm{p}<0.014$, respectively).

Conclusions: Morphologic characteristics of the CC can be helpful to anticipate schizophrenia especially in patients' family, and it can be used for suitable and faster treatment to prevent progressive cognitive dysfunction.

Keywords: Corpus Callusum, Schizophrenia, MRI, Positive and Negative Syndrome Scale
\end{abstract}

\section{Introduction}

The Corpus Callosum (CC) is the largest inter-hemispheric pathway in the brain and has been widely studied for its role in hemispheric communication and in lateralized brain function and behaviors. The corpus callosum morphology varies with age, sex, and intellectual ability $(1,2)$. Moreover, several neural disorders affect the structural integrity and connectivity of the CC. For example, variations in the CC size and shape are associated with

\section{Corresponding author:}

Dr. Shahab Bagherzadeh Shahidi, Department of psychiatry, Kashan University of medical Sciences, Kashan, Iran. Tel: +98.3154550021, Email: sshahidi95@yahoo.com

Received: May 03, 2016, Accepted: August 12, 2016, Published: October 2017

iThenticate screening: August 03, 2016, English editing: September 20, 2016, Quality control: September 15, 2017

(C) 2017 The Authors. This is an open access article under the terms of the Creative Commons Attribution-NonCommercialNoDerivs License, which permits use and distribution in any medium, provided the original work is properly cited, the use is non-commercial and no modifications or adaptations are made. 
disease processes in autism and schizophrenia (3-6). The healthy brain exhibits both structural and functional asymmetries (7). A reduction in the CC area has been reported in schizophrenia mostly for the failure of the left hemisphere dominance (8). Structural deficits of CC may correlate to the abnormal asymmetry of intra-hemispheric connectivity in schizophrenia (9). The left hemisphere is dominant for language and handedness and the right hemisphere for nonverbal functions, such as spatial attention and the processing of faces (10-12). Also, in schizophrenia patients, asymmetry of language-related processing is decreased (13-17). Magnetic resonance imaging (MRI) studies showed that the CC size was positively correlated with verbal memory capacity and semantic coding test performance (18). The results of a 2001 study by Bradley and colleges showed that the morphology variants of the CC were divided into eight shapes that form more than 90\% shapes of the CC (19). Different shapes of the CC include splenial bulbosity (type 1), overall thickness (type 2), overall curvature (type 3), anterior body thickness (type 4), thick and arched anterior body (type 5), thin and arched anterior body (type 6), splenial thickness (type 7) and arch mid-body (type 8). The results of some studies demonstrated that schizophrenia is associated with a reduced CC area when compared with the results from healthy controls (20). Despite a large number of studies, few systematic findings are related to sexual dimorphism of the $\mathrm{CC}$ in patients with schizophrenia. Also, the influence of illness chronicity was vague to be elucidated. Moreover, several cross-sectional studies showed that age had no effect at onset and illness duration on the CC morphology $(21,22)$. However, others have shown decreases in the CC size with the duration of illness (23), which varies between the first episode and established schizophrenia (24). Some studies offer the best solution $(25,26)$ and have shown longitudinal changes in the CC pointing to an abnormality in the developmental pathway; however, the logistic difficulties of longitudinal studies limit the conclusions that can be drawn morphology in chronic schizophrenia. The importance of the CC in patients with schizophrenia is because of its probable role in reducing lateralization and sexual dimorphism characteristics (27). The results of one study showed that the mid-saggital CC cross-sectional area was proportionately larger in female (28). The corpus callosum has an anatomically fixed role in reinforcement of cognitive, motor, and sensory information (29). The postmortem anatomical studies showed an increase or decrease in thickness and decrease in the cross-sectional area of the $\mathrm{CC}$ in schizophrenic patients (20). In order to show the effect of illness characteristics and positive or negative symptoms on the CC morphology in schizophrenic patients, we examined indices of CC structure using an MRI in patients with schizophrenia and healthy people. This study was designed to investigate the cross-sectional area and morphology of the CC in schizophrenia patients and normal controls.

\section{Material and Methods}

\subsection{Research design}

This case-control study was conducted to compare the cross-sectional area and morphology of the CC in patients with chronic schizophrenia (study group) and healthy population (control group) with age range of 20-50 years. Sixty-three consecutive individuals with schizophrenia symptoms who were examined and diagnosed with schizophrenia according to the DSM-IV-TR criteria in the Kashan Kargarnejad Psychiatry Hospital were enrolled in this study between January 2013 and December 2014. The control group consisted of 63 consecutive individuals admitted to other general hospital (Naghavi) at the same time and city for taking an MRI due to different reasons. Both of the mentioned hospitals are governmental.

\subsection{Sample size and sampling method}

Sixty-three consecutive individuals with schizophrenia symptoms who were examined and diagnosed with schizophrenia according to the DSM-IV-TR criteria in the Kashan Kargarnejad Psychiatry Hospital were enrolled in this study between January 2013 and December 2014. The control group consisted of 63 consecutive individuals admitted to other general hospital (Naghavi) at the same time and city for taking an MRI due to different reasons. Both of the mentioned hospitals are governmental. The sample size was calculated with a significance level of 0.05 (two-sided) and a power level of 0.90. Sample size calculation was performed based on a pilot study using a formula to compare means of a quantitative variable in two independent groups $(\alpha=0.05, \beta=0.2)$. The sampling method was simple and convenient and participants enrolled the study by random selection method.

\subsection{Inclusion and exclusion criteria for cases}

Inclusion criteria were patients diagnosed with a schizophrenia disorder according to the DSM-IV-TR criteria. Individuals in the study group were excluded from the study if they had psychiatric disorders such as anxiety and mood disorders, an acute medical illnesses such as uremic syndrome, liver or kidney encephalopathy, history of alcohol dependence, HIV positive, use of intravenous amphetamine, neurological disorders, materials and inhalant abuse in last 30 days, history of head injury with loss of consciousness for more than 30 minutes, neurological sequel in imaging in the last 6 months. We did not have any missing value in our study. 


\subsection{Inclusion and exclusion criteria for controls}

Inclusion criteria for the control group consisted of individuals admitted to Naghavi hospital (Naghavi) for an MRI due to different reasons. Individuals in the control group were excluded from the study if they had psychiatric disorders such as anxiety and mood disorders, the acute medical illnesses such as uremic syndrome, liver or kidney encephalopathy, history of alcohol dependence, HIV positive, use of intravenous amphetamine, neurological disorders, materials and inhalant abuse in last 30 days, history of head injury with loss of consciousness for more than 30 minutes, neurological sequel in imaging in the last 6 months. We did not have any missing value in our study.

\subsection{Procedures and data collection}

The severity of general psychopathological symptoms and overall functioning were evaluated using the positive and negative syndrome scale (PANSS) in patients with schizophrenia. Data regarding patients' characteristics and PANSS were collected by one clinical psychologist. All MRIs were interpreted by one radiologist.

\subsection{Magnetic Resonance Scanning and Image Processing}

All subjects were scanned on a 1T GE Philips MRI machine. The imaging was two-dimensional in the steady-state protocol T2 sequence with $3 \mathrm{~mm}$ sagittal slices. Imaging parameters were time-to-echo, $100 \mathrm{~ms}$; time-to-repetition, $4914 \mathrm{~ms}$; flip angle, $90^{\circ}$; field of view, 290/1:3 cm matrix. Anteroposterior length of CC was measured from genu to splenium, one third of sagittal slices' thickness were used for measuring surface area. Morphology, area, and length of the anteroposterior of midsagittal CC were measured by a radiologist and compared in subjects in both groups.

\subsection{Bias and confounders and statistical analysis}

Specifically, selection bias is a common type of bias in case-control studies. With a randomized sampling method, we managed the potential confounders and avoided the bias. The Kolmogorov-Smirnov test was used to consider normality of data distribution. Also, chi-square test, t-test, Pearson product-moment correlation coefficient test, bivariate analysis of variance and logistic regression were used to test the association between different variables using IBM@ SPSS $\odot$ Statistics version 20 (IBM $\odot$ Corp., Armonk, NY, USA)

\subsection{Ethics of research}

This study received ethics approval (No. 2587, date: 2012/10/1) from our local institutional review committees. A written informed consent was obtained from all the participants, and the patients' information was kept confidential.

\section{Results}

From a total of 126 participants, $55.6 \%$ were male ( $n=35$, in each group). The results of the Kolmogorov-Smirnov test showed that, among all variables (including age, anteroposterior length, and surface area of the CC) just age had no normal distribution. The median and inter quartile range (IQR) of age in the participants of both groups were 38 and 13, respectively. The youngest age was 20 years old and the oldest was 49 in both groups. There was no significant difference between the two groups regarding age and sex. In addition, the possible confounding role of these variables was controlled in the logistic regression model. The percentages of all types of the CC in the control group were more than the schizophrenia group, except two types, including splenial bulbosity (Type 1) and splenial thickness (Type 7), which were 54\%, 33.3\% and $15.9 \%, 4.8 \%$ in the schizophrenia and control groups, respectively (Table 1). Also, splenial bulbosity (Type 1) is the most common type of CC in both genders of the two groups except male schizophrenic patients (Table 2). The mean CC area was $0.61 \mathrm{~mm} \pm 0.108 \mathrm{~mm}$ in the schizophrenia group and $0.8 \mathrm{~mm} \pm 0.17 \mathrm{~mm}$ in the control group, which was statistically significant $(\mathrm{p}<0.001)$. Moreover, the anteroposterior length of the CC was $69 \mathrm{~mm} \pm 4.2 \mathrm{~mm}$ in the schizophrenia group and $69.4 \mathrm{~mm} \pm 7 \mathrm{~mm}$ in the control group $(p=0.75)$, which was not statistically significant. There was a significant difference between the anteroposterior length and area of the $\mathrm{CC}$ regarding gender in both groups $(\mathrm{p}=0.014)$; in females, the anteroposterior length of the $\mathrm{CC}$ in the schizophrenia group was further compared with the control group; however, in males, the anteroposterior length of the $\mathrm{CC}$ in the schizophrenia group was less than that in the control group. On the other hand, the mean of CC area was more in both male and female participants in the control group compared with that in the schizophrenia group $(\mathrm{p}=0.001)$, (Table 3). In general, the mean age of men $(\mathrm{n}=70)$ was 37 years old and for women $(n=56)$ was 37.75 ; thus, the difference was not statistically significant $(\mathrm{p}=0.5)$. The mean of severity of positive and negative symptoms in the schizophrenic patients and the anteroposterior length and area of the CC in both groups in males were more than females (Table 4). According to the results of the present study, there was an inverse correlation between positive and negative symptoms $(\mathrm{p}=0.002)$. Also, positive correlation was found between positive and negative symptoms and symptom severity $(\mathrm{p}=0.001)$. Moreover, there was a positive 
correlation between the area and anteroposterior length of the $\mathrm{CC}$ in both groups ( $\mathrm{p}=0.001$ ) (Table 5). Our study showed that female gender significantly increased the odds of schizophrenia $(\mathrm{OR}=0.22$, CI: 0.068-0.69) (Table 6).

Table 1. Comparison of Corpus Callosum Morphology Between the Two Groups ${ }^{\mathrm{a}}$

\begin{tabular}{|l|l|l|}
\hline Morphology of CC & Schizophrenia; $n(\%)$ & Control; $n(\%)$ \\
\hline Splenial bulbosity (type 1) & $34(54)$ & $21(33.3)$ \\
\hline Overall thickness (type 2) & $14(22.2)$ & $18(28.6)$ \\
\hline Overall curvature (type 3) & $3(4.8)$ & $8(12.7)$ \\
\hline Anterior body thickness (type 4) & 0 & $2(3.2)$ \\
\hline Thick and arched anterior body (type 5) & $1(1.6)$ & $5(7.9)$ \\
\hline Thin and arched anterior body (type 6) & $1(1.6)$ & $3(4.8)$ \\
\hline Splenial thickness (type 7) & $10(15.9)$ & $5(4.8)$ \\
\hline Arch mid-body (type 8) & 0 & $1(1.6)$ \\
\hline
\end{tabular}

${ }^{a}$ Abbreviation: CC, corpus callosum.

Table 2. Comparison of Corpus Callosum Morphology Between the Two Groups Based on Gender

\begin{tabular}{|l|l|l|l|l|}
\hline \multirow{2}{*}{ Morphology of CC } & \multicolumn{3}{|l|}{ Female } & Male \\
\cline { 2 - 5 } & Control & Schizophrenia & Control & Schizophrenia \\
\hline Splenial bulbosity (Type 1) & 53.6 & 50 & 54.3 & 20 \\
\hline Overall thickness (Type 2) & 21.4 & 17.9 & 22.9 & 37.1 \\
\hline Overall curvature (Type 3) & 3.6 & 10.7 & 5.7 & 14.3 \\
\hline Anterior body thickness (Type 4) & 0 & 0 & 0 & 5.7 \\
\hline Thick and arched anterior body (Type 5) & 3.6 & 7.1 & 0 & 8.6 \\
\hline Thin and arched anterior body (Type 6) & 3.6 & 3.6 & 0 & 5.7 \\
\hline Splenial thickness (Type 7) & 14.2 & 10.7 & 17.1 & 5.7 \\
\hline Arch mid-body (Type 8) & 0 & 0 & 0 & 2.9 \\
\hline
\end{tabular}

Table 3. Comparison of Magnetic Resonance Imaging Finding in Both Groups

\begin{tabular}{|c|c|c|c|c|}
\hline \multicolumn{2}{|l|}{ Variables } & $\begin{array}{l}\text { Schizophrenia, Mean } \\
\text { (SD) }\end{array}$ & $\begin{array}{l}\text { Control, Mean } \\
\text { (SD) }\end{array}$ & $\begin{array}{l}\mathrm{p}- \\
\text { value }\end{array}$ \\
\hline \multicolumn{2}{|l|}{ Age (year) } & $37.4(7.56)$ & $37.2(7.8)$ & 0.5 \\
\hline \multirow[t]{3}{*}{ PANSS } & Positive symptom & $34.2(6.9)$ & - & \multirow[t]{3}{*}{-} \\
\hline & Negative symptom & $34.2(6.7)$ & - & \\
\hline & Symptom severity & $139(14.08)$ & - & \\
\hline \multirow{2}{*}{ MRI finding } & Anteroposterior length of the $\mathrm{CC}$ & $69(4.2)$ & $69.4(7)$ & 0.75 \\
\hline & Area of CC & $0.61(0.108)$ & $0.8(0.17)$ & $<0.001$ \\
\hline \multirow{2}{*}{$\begin{array}{l}\text { Anteroposterior } \\
\text { length of the CC }\end{array}$} & Female & $67.9(3.8)$ & $67.7(6.2)$ & 0.014 \\
\hline & Male & $69.9(4.4)$ & $70.7(7.3)$ & 0.014 \\
\hline \multirow{2}{*}{$\begin{array}{l}\text { Surface area of the } \\
\text { CC }\end{array}$} & Female & $0.57(0.07)$ & $0.73(0.17)$ & 0.001 \\
\hline & Male & $0.64(0.11)$ & $0.86(0.15)$ & 0.001 \\
\hline
\end{tabular}

Table 4. Mean of Symptom Severity and Anteroposterior Length and Area of the Corpus Callosum Based on Sex

\begin{tabular}{|c|c|c|c|c|}
\hline Variables & Sex & Mean & SD & p-value \\
\hline \multirow{2}{*}{ Anteroposterior length of the $\mathrm{CC}$} & Male & 70.38 & 6.05 & \multirow{2}{*}{0.014} \\
\hline & Female & 67.83 & 5.14 & \\
\hline \multirow[t]{2}{*}{ Surface area of the CC } & Male & 0.75 & 0.17 & \multirow[t]{2}{*}{0.001} \\
\hline & Female & 0.65 & 0.15 & \\
\hline \multirow[t]{2}{*}{ Positive symptom severity } & Male & 34.4 & 5.82 & \multirow[t]{2}{*}{0.8} \\
\hline & Female & 34.14 & 8.32 & \\
\hline \multirow[t]{2}{*}{ Negative symptom severity } & Male & 35.22 & 6.51 & \multirow[t]{2}{*}{0.19} \\
\hline & Female & 33 & 6.85 & \\
\hline \multirow[t]{2}{*}{ Total severity } & Male & 139 & 12.98 & \multirow[t]{2}{*}{0.9} \\
\hline & Female & 139 & 15.6 & \\
\hline \multirow[t]{2}{*}{ Age (year) } & Male & 37 & 7.82 & \multirow[t]{2}{*}{0.5} \\
\hline & Female & 37.75 & 7.52 & \\
\hline
\end{tabular}


http://www.ephysician.ir

Table 5. Correlation Between Symptom Severity and Anteroposterior Length and Area of the Corpus Callosum

\begin{tabular}{|l|l|l|l|l|l|l|}
\hline Variables & & $\begin{array}{l}\text { Positive } \\
\text { symptom }\end{array}$ & $\begin{array}{l}\text { Negative } \\
\text { symptom }\end{array}$ & $\begin{array}{l}\text { Symptom } \\
\text { severity }\end{array}$ & $\begin{array}{l}\text { Anteroposterior } \\
\text { length of the CC }\end{array}$ & $\begin{array}{l}\text { Area of } \\
\text { the CC }\end{array}$ \\
\hline Positive symptom & Correlation & 1 & -0.392 & 0.461 & 0.11 & 0.005 \\
\cline { 2 - 7 } & $p$-value & - & 0.002 & 0.001 & 0.386 & 0.971 \\
\hline \multirow{2}{*}{ Negative symptom } & Correlation & -0.392 & 1 & 0.503 & -0.013 & 0.07 \\
\cline { 2 - 7 } & $p$-value & 0.002 & - & 0.001 & 0.917 & 0.55 \\
\hline \multirow{2}{*}{ Symptom severity } & Correlation & 0.461 & 0.503 & 1 & 0.051 & 0.038 \\
\cline { 2 - 7 } & $p$-value & 0.001 & 0.001 & - & 0.69 & 0.77 \\
\hline \multirow{2}{*}{$\begin{array}{l}\text { Anteroposterior } \\
\text { length of the CC }\end{array}$} & Correlation & 0.111 & -0.013 & 0.05 & 1 & 0.001 \\
\hline $\begin{array}{l}\text { Surface area of the } \\
\text { CC }\end{array}$ & Correlation & 0.386 & 0.917 & 0.69 & - & 1 \\
\cline { 2 - 7 } & $p$-value & 0.005 & 0.077 & 0.038 & 0.53 & - \\
\hline
\end{tabular}

Table 6. Parameters of Logistic Regression to Predict Schizophrenia

\begin{tabular}{|l|l|l|l|}
\hline Variable & OR & $95 \%$ CI & $p$-value \\
\hline Age (year) & 1.01 & $0.95-1.08$ & 0.76 \\
\hline Sex (female) & 0.22 & $0.068-0.69$ & 0.01 \\
\hline Anteroposterior length of the CC & 1.1 & $0.99-1.22$ & 0.084 \\
\hline
\end{tabular}

OR: Odds ratio

\section{Discussion}

The purpose of this study was to evaluate the morphological differences of the CC between patients with chronic schizophrenia and healthy people as well as to study the relationship between the characteristics of the CC and schizophrenia severity. To the best of our knowledge, no study has been conducted in Iran to examine the association between the characteristics of the $\mathrm{CC}$ and schizophrenia severity.

\subsection{Shape of the Corpus Callosum}

Results of the present study showed that two types of the CC (Type 1 and 7) in patients with chronic schizophrenia were more than in the control group. Also, splenial bulbosity (Type 1) was the most common shape of the CC in both groups. Splenial bulbosity (Type 1) and splenial thickness (Type 7) have smaller thickness in isthmus and postmid-body of the CC compared with other types of the CC. Similar to our study, Balevich et al. (30) suggested that a chronic phase of schizophrenia is characterized by deficits in posterior of the $\mathrm{CC}$; also they found that the first episodes of schizophrenia are characterized by deficiencies in frontal connections. However, Waltefang et al. (31) found reductions in the size of anterior callosum for the first episode and established schizophrenia and, unlike our in study, showed an increase in thickness in the splenium and isthmus. Moreover, they showed that (24) a decrease in width of the $\mathrm{CC}$ in anterior genu in patients with chronic schizophrenia was fewer than in the first episode. Also, in a study of Keshvan (2002) and Bechmann (2003) et al. on first-episode schizophrenia showed a smaller CC, anterior genu, body, isthmus, and anterior splenium than normal controls, and they indicated predominantly anterior and posterior changes of the area of the CC $(32,33)$. The corpus callosum in patients with schizophrenia appears to be different from healthy controls and across different stages of illness $(24,31)$. In our study, the most common shapes of the $\mathrm{CC}$ in both genders of the control group and females of the schizophrenia patients were splenial bulbosity (Type 1); however, in males of the schizophrenia patients, the overall thickness type (Type 2) and splenial bulbosity (Type 1) were the second most common shapes. Similar to our study, Gupta et al. (34) in India did not find any difference in the morphology of the CC based on sex. However, Peterson and colleagues (19) claimed that the anterior body of the $\mathrm{CC}$ in males was thinner compared with females. Also, Luders and Tuner et al. $(35,36)$ suggested that the morphology of the $\mathrm{CC}$ has a significant difference in both sexes. As observed in related studies, differences in the shapes of the $\mathrm{CC}$ between schizophrenia and control groups as well as among genders in different studies could be related to the number of samples included in the study and breed of the participants and methods of sample collection and assessment studies, which need to be further investigated.

\subsection{Area and Length of the Corpus Callosum}

In our study, the CC area was significantly reduced in schizophrenia patients compared with the control group in line with most of the studies conducted so far (37). Colinson et al. (38) found that the area of the CC was 
significantly reduced in schizophrenic patients compared with the controls. Moreover, patients with chronic schizophrenia had a larger CC area compared with the first episode and controls. However, no significant difference in the CC was found between genders in either patients or controls. Contrary to the study of Colinson, our study showed significant differences in anteroposterior length and area of the CC based on sex in different groups, so that female patients with schizophrenia significantly increased the odds of schizophrenia. Also, Arone et al. (20) suggested that the area of the $\mathrm{CC}$ in the schizophrenia group was smaller than the control group and in chronic patients was more than first episode of schizophrenia. Nevertheless, Narr et al. (3-6) showed increase of maximum width of anterior and posterior of the $\mathrm{CC}$ in men of the schizophrenia group compared with those of the control group. Frumin et al. (39) found no significant difference in the area of CC between the first episode of schizophrenia and the first episode of psychosis with a mood disorder; however, there were structural differences in shapes of the $\mathrm{CC}$ in the two groups. Moreover, the anteroposterior length of the $\mathrm{CC}$ was little more in the control group; however, it was not statistically significant. Walterfang and colleagues' study showed significant area reductions in the midanterior and posterior areas in patients with first episode and overall reduction in chronic schizophrenia. Additionally, negative correlations were seen between the duration of illness and the CC area (40). Moreover, Walterfang examined callosal morphology in a large sample of patients and found decreases in callosal width in the anterior genu in schizophrenia patients. Mitelman and colleagues (41) demonstrated a smaller CC size in patients with schizophrenia compared with normal controls at baseline and after four years' follow-up. The authors also found that the $\mathrm{CC}$ was more elongated in patients with poor outcome compared with those with a good outcome. Our study showed that, regarding gender, the length and area of the $\mathrm{CC}$ in males were more than those of females in both groups. Furthermore, Suganthy and Mourgela $(42,43)$ found that the anteroposterior length of the CC in males was more than that of female; however, the CC area was the same for both genders. Also, Gupta (34) perceived that the area and length of the $\mathrm{CC}$ in two genders were different that were significant. Contrary to our study, Luders (35) did not find any difference between the area and length of $\mathrm{CC}$ in two genders. In the general healthy population, most of the MRI investigations have reported larger CC in females, although studies with the opposite finding also appear in the literature. In a meta-analysis of 43 MRI studies, which reported the effects of sex and age on the CC morphology, Driesen and Raz (44) found that an absolute CC area was more in males compared with females, but, when overall brain size and volume were controlled for the direction of the sex, the difference was reversed. Moreover, Jancke and colleagues (45) showed that the only apparent influence of sex was on CC ratios, which were larger in females. Whether this difference is also partially attributable to generally larger CC ratios in Asian people remains to be determined by cross-cultural studies; presently, however, little data exist that can clarify the correlation between CC and brain volume in this population. In the Takeda et al. (46) study, in a CC increased with age, no sex differences in a regional size of the $\mathrm{CC}$ were observed. The differences of anteroposterior length and area of the $\mathrm{CC}$ in genders can be related to the differences in function of the brain. Neuropsychological studies and last MRI imaging findings in males showed that brain functions were mostly concentrated on the frontal cortex (47). The results of the present study indicated that the mean of positive and negative symptom severity scores and anteroposterior length and area of the $\mathrm{CC}$ in males were more than those in females. Based on the study of Meng et al. (48), from infancy until old age by diffuse tensor imaging (DTI), they received that transcalossal connections in dorsolateral and ventrolateral cortex of the frontal cortex were prominently correlated with aging. However, they were less correlated with temporal, posterior, and visual cortexes. Kate Smith et al. (49) showed that DTI abnormalities between two hemispheres of the brain in patients with chronic schizophrenia were more related to the posterior part of the frontal lobe. It is believed that changes in the $\mathrm{CC}$ occur secondary to age-related changes or frontal lobe pathology (50). Therefore, we can conclude that the $\mathrm{CC}$ changes are associated with changes in the frontal lobe, which require further consideration. Better understanding of the differences in the corpus callosum size in patients requires more investigation such as the implementation of the results of electrophysiological findings. Paying attention to some characteristics, such as intelligence and people skills can be helpful in interpreting the different results of brain imaging findings. In a study conducted on patients with schizophrenia in patients without auditory hallucination reduced fractional anisotropy in arcuate fasciculus, uncinate fasciculus and inferior longitudinal fasciculus and in patients with auditory hallucination fractional anisotropy in the CC and arcuate fasciculus showed an increase. This evidence showed abnormalities in white matter fiber bundles in frontal and temporal lobes. In addition, frontotemporal connections of the brain and other white matter areas are less probable to be involved in schizophrenia. These areas include CC, anterior arm of internal capsule, and fornix (29). These results demonstrated that, in schizophrenia, greater reductions could suggest a specific failure of myelination that occurs normally in childhood and adolescence $(22,32,33,51)$. However, in our study, no association was found between severity of schizophrenia and the anteroposterior length and area of CC. This difference may be due to a small number of patients, the methods to evaluate patients, and a low number of physicians evaluating patients. Therefore, further studies with larger sample sizes, more precise imaging methods, and more professionals are 
needed to evaluate the symptoms of schizophrenia. The results of this study showed the morphological differences of the corpus callosum in the two groups and its relation to age, sex, and symptoms of schizophrenia. Therefore, the pathological findings of the corpus callosum are related to the pathologies of different lobes of the brain, especially the frontal lobe. Morphologic characteristics of the $\mathrm{CC}$ will be helpful to anticipate schizophrenia, especially in a patient's family, and it can be used for suitable and faster treatment to prevent progressive cognitive dysfunction. The main strength of our study is that we not only consider the association between the CC characteristics and schizophrenia but also study the relationship between the CC features and severity of schizophrenia. This study has a few limitations that provide opportunities for future research. First, the use of a cross-sectional design, which limits the generalizability of findings from this study due to a small number of samples; second, lack of enough knowledge on age of disease onset, disease duration, and duration of exposure to antipsychotic medications; third, bias in recruitment characteristics.

\section{Conclusions}

The results of this study showed the morphological differences of the corpus callosum in the two groups and its relation to age, sex, and symptoms of schizophrenia. Therefore, the pathological findings of the corpus callosum are related to the pathologies of different lobes of the brain, especially the frontal lobe. Morphologic characteristics of the CC will be helpful to anticipate schizophrenia, especially in a patient's family, and it can be used for suitable and faster treatment to prevent progressive cognitive dysfunction. However, further investigations are necessary for evaluation and development of this diagnostic method.

\section{Acknowledgments:}

This study was part of a residency dissertation funded by deputy of research of Kashan University of Medical Sciences (grant no: 9287). We would like to thank all of the participants who helped us in this study.

\section{Conflict of Interest:}

There is no conflict of interest to be declared.

Authors' contributions:

All authors contributed to this project and article equally. All authors read and approved the final manuscript.

\section{References:}

1) Luders E, Thompson PM, Toga AW. The development of the corpus callosum in the healthy human brain. J Neurosci. 2010; 30(33): 10985-90. doi: 10.1523/JNEUROSCI.5122-09.2010. PMID: 20720105, PMCID: PMC3197828.

2) Luders E, Thompson PM, Narr KL, Zamanyan A, Chou YY, Gutman B, et al. The link between callosal thickness and intelligence in healthy children and adolescents. Neuroimage. 2011; 54(3): 1823-30. doi: 10.1016/j.neuroimage.2010.09.083. PMID: 20932920, PMCID: PMC3110814.

3) Frazier TW, Hardan AY. A meta-analysis of the corpus callosum in autism. Biol Psychiatry. 2009; 66(10): 935-41. doi: 10.1016/j.biopsych.2009.07.022. PMID: 19748080, PMCID: PMC2783565.

4) Innocenti GM, Ansermet F, Parnas J. Schizophrenia, neurodevelopment and corpus callosum. Mol Psychiatry. 2003; 8(3): 261-74. doi: 10.1038/sj.mp.4001205. PMID: 12660799.

5) Narr KL, Thompson PM, Sharma T, Moussai J, Cannestra AF, Toga AW. Mapping morphology of the corpus callosum in schizophrenia. Cereb Cortex. 2000; 10(1): 40-9. doi: 10.1093/cercor/10.1.40. PMID: 10639394.

6) Paul LK, Brown WS, Adolphs R, Tyszka JM, Richards LJ, Mukherjee P, et al. Agenesis of the corpus callosum: genetic, developmental and functional aspects of connectivity. Nat Rev Neurosci. 2007; 8(4): 287-99. doi: 10.1038/nrn2107. PMID: 17375041.

7) Renteria ME. Cerebral asymetry: a quantitative, multifactorial, and plastic brain phenotype. Twin Res Hum Gent. 2012; 15(3): 401-13. doi: 10.1017/thg.2012.13. PMID: 22856374.

8) Mitchell RL, Crow TJ. Right hemispher language functions and schizophrenia: the forgotten hemispher? Brain. 2005; 128(Pt 5): 963-78. doi: 10.1093/brain/awh466. PMID: 15743870.

9) Ribolsi M, Daskalakis ZJ, Siracusano A, Koch G. Abnormal asymmetry of brain connectivity in schizophrenia. Front Human Neuroscience. 2014; 8: 1010. doi: 10.3389/fnhum.2014.01010. PMID: 25566030, PMCID: PMC4273663.

10) Corbalis MC. Left brain right brain: facts and fantasies. PLoS Biol. 2014; 12(1): e1001767. doi: 10.1371/journal.pbio.1001767. PMID: 24465175, PMCID: PMC3897366.

11) Cai Q, Vander haegen L, Brysbaert M. Complementary hemispheric spacialization for language production and visuspatial attention. Proc Natl Acad Sci U S A. 2013; 110(4): 322-30. doi: 10.1073/pnas.1212956110. PMID: 23297206, PMCID: PMC3557046. 
12) Dundas EM, Plaut DC, Behrmann M. An ERP investigation of the co-development of hemispheric lateralization of face and word recognition. Neuropsychologia. 2014; 61: 315-23. doi: 10.1016/j.neuropsychologia.2014.05.006. PMID: 24933662, PMCID: PMC4251456.

13) Sommer IE, Ramsy NF, Kahn RS. Language lateralization in schizophrenia, an fMRI study. schizophr Res. 2001; 52(1-2): 57-67. PMID: 11595392.

14) Sommer I, Ramsey N, Kahn R, Aleman A, Bouma A. Handedness, language lateralizationand anatomical asymmetry in schizophrenia: meta analysis. $\mathrm{Br} \mathrm{J}$ psychiatry. 2001; 178: 344-51. doi: 10.1192/bjp.178.4.344. PMID: 11282814.

15) Sommer IE, Ramsey NF, Mandl RC, Kahn RS. Language lateralization infemale patients with schizophrenia, an fMRI study. schizophr res. 2003; 60(2-3): 183-90. PMID: 12591582.

16) Sommer IE, Ramsey NF, Mandl RC, van Oel CJ, Kahn RS. Language activation in monozygotic twins discordant for schizophrenia. Biol Psychiatry. 2004; 184: 128-35. PMID: 14754824.

17) Bleich-Cohen M, Handler T, Kotler M, Strous RD. Reduced language lateralization in first-episode schizophrenia: an fMRI index of functional asymmetry. Psychiatry Res. 2009; 171(2): 82-93. doi: 10.1016/j.pscychresns.2008.03.002. PMID: 19185468.

18) Kozlovskiy S, Vartanov AV, Pyasik M, Nikonova E. Functional role of corpus callosum regiones in human memory functioning. International journal of psycophisiology. 2012; 85(3): 396-7. doi: 10.1016/j.ijpsycho.2012.07.092.

19) Peterson BS, Feineigle PA, Staib LH, Gore JC. Automated measurement of latent morphological features in the human corpus callosum. Hum Brain Mapp. 2001; 12(4): 232-45. PMID: 11241874.

20) Arnone D, McIntosh AM, Tan GM, Ebmeier KP. Meta-analysis of magnetic resonance imaging studies of the corpus callosum in schizophrenia. Schizophr Res. 2008; 101(1-3): 124-32. doi: 10.1016/j.schres.2008.01.005. PMID: 18289833.

21) John JP, Shakeel MK, Jain S. Corpus callosal area differences and gender dimorphism in neurolepticnai"ve, recent-onset schizophrenia and healthy control subjects. Schizophr Res. 2008; 103(1-3): 11-21. doi: 10.1016/j.schres.2008.04.035. PMID: 18585006, PMCID: PMC2605782.

22) Bersani G, Quartini A, Iannitelli A, Paolemili M, Ratti F, Di Biasi C, et al. Corpus callosum abnormalities and potential age effect in men with schizophrenia: an MRI comparative study. Psychiatry Res. 2010; 183(2): 119-25. doi: 10.1016/j.pscychresns.2010.04.011. PMID: 20599365.

23) Downhill JE Jr, Buchsbaum MS, Wei T, Spiegel-Cohen J, Hazlett EA, Haznedar MM, et al. Shape and size of the corpus callosum in schizophrenia and schizotypal personality disorder. Schizophr Res. 2000; 42(3): 193-208. PMID: 10785578.

24) Walterfang M, Wood AG, Reutens DC, Wood SJ, Chen J, Velakoulis D, et al. Morphology of the corpus callosum at different stages of schizophrenia: cross-sectional study in first-episode and chronic illness. $\mathrm{Br} \mathrm{J}$ Psychiatry. 2008; 192(6): 429-34. doi: 10.1192/bjp.bp.107.041251. PMID: 18515892.

25) Keller A, Jeffries NO, Blumenthal J, Clasen LS, Liu H, Giedd JN, et al. Corpus callosum development in childhood-onset schizophrenia. Schizophr Res. 2003; 62(1-2): 105-14. PMID: 12765750.

26) Walterfang M, Yung A, Wood AG, Reutens DC, Phillips L, Wood SJ, et al. Corpus callosum shape alterations in individuals prior to the onset of psychosis. Schizophr Res. 2008; 103(1-3): 1-10. doi: 10.1016/j.schres.2008.04.042. PMID: 18562178.

27) Panizzon MS, Hoff AL, Nordahl TE, Kremen WS, Reisman B, Wieneke M, et al. Sex differences in the corpus callosum of patients with schizophrenia. Schizophr Res. 2003; 62(1-2): 115-22. PMID: 12765751.

28) Ardekani BA, Figarsky K, Sidtis JJ. Sexual dimorphismin human corpus callosum: an MRI study using the OASIS brain database. Cerebral cortex. 2012; 23(10): 2514-120. doi: 10.1093/cercor/bhs253. PMID: 22891036 , PMCID: PMC3767965.

29) Sadock B. Kaplan \& Sadock Comprehensive text book of psychiatry. 9th ed. 2009.

30) Balevich EC, Haznedar MM, Wang E, Newmark RE, Bloom R, Schneiderman JS, et al. Corpus callosum size and diffusion tensor anisotropy in adolescents and adults with schizophrena. Psychiatry Res. 2015; 231(3): 244-51. doi: 10.1016/j.pscychresns.2014.12.005. PMID: 25637358, PMCID: PMC4363270.

31) Walterfang M, Wood AG, Reutens DC, Wood SJ, Chen J, Velakoulis D, et al. Corpus callosum size and shape in first-episode affective and schizophrenia-spectrum psychosis. psychiatry Res. 2009; 173(1): 77-82. doi: 10.1016/j.pscychresns.2008.09.007. PMID: 19447585.

32) Bachmann S, Pantel J, Flender A, Bottmer C, Essig M, Schröder J. Corpus callosum in first-episode patients with schizophrenia-a magnetic resonance imaging study. Psychol Med. 2003; 33(6): 1019-27. PMID: 12946086. 
33) Keshavan MS, Diwadkar VA, Harenski K, Rosenberg DR, Sweeney JA, Pettegrew JW. Abnormalities of the corpus callosum in first-episode, treatment nä"ve schizophrenia. J Neurol Neurosurg Psychiatry. 2002; 72(6): 757-60. PMID: 12023420, PMCID: PMC1737922.

34) Gupta T, Singh B, Kapoor K, Gupta M, Kochhar S. Age and sex related variations in corpus callosal morphology. Nepal Med Coll J. 2008; 10(4): 215-21. PMID: 19558056.

35) Luder E, Narr KL, Zaidel E, Thampson PM, Toga AW. Gender effects on callosal thickness in scaled and unscaled space. Neuroreport. 2006; 17(11): 1103-6. doi: 10.1097/01.wnr.0000227987.77304.cc. PMID: 16837835 .

36) Tuncer MC, Hatipoglu ES, Osates M. sexual dimophisms and handedness in the human corpus callusum based on magnetic resonance imaging. Surg Radial anat. 2005; 27(3): 254-9. doi: 10.1007/s00276-0040308-1. PMID: 15682276.

37) Woodruff PW, McManus IC, David AS. Meta-analysis of corpus-callosum size in schizophrenia. J Neurol Neurosurg Psychiatr. 1995; 58(4): 457-61. PMID: 7738554, PMCID: PMC1073433.

38) Colinson SL, Gan SC, Woon PS, Kuswanto C, Sum MY, Yang GL, et al. Corpus callosum morphology in first-episode and chronic schizophrenia: combined magnetic resonance and diffusion tensor imaging study of chinese Singaporean patients. B J Psych. 2014; 204(1): 55-60. doi: 10.1192/bjp.bp.113.127886. PMID: 24202961.

39) Frumin M, Golland P, Kikinis R, Hirayasu Y, Salisbury DF, Hennen J, et al. Shape Differences in the corpus callosum in First-Episode schizophrenia and First-Episode Psychotic Affective Disorder. Am J Psychiatry. 2002; 159(5): 866-8. doi: 10.1176/appi.ajp.159.5.866. PMID: 11986146, PMCID: PMC2845853.

40) Jiang H, van Zijl PC, Kim J, Pearlson GD, Mori S. resource program for diffusion tensor computation and fiber bundle tracking. Comput Methods Programs Biomed. 2006; 81)2): 106-16. doi: 10.1016/j.cmpb.2005.08.004. PMID: 16413083.

41) Mitelman SA, Nikiforova YK, Canfield EL, Hazlett EA, Brickman AM, Shihabuddin L, et al. A longitudinal study of the corpus callosum in chronic schizophrenia. Schizophr Res. 2009; 114(1-3): 144-53. doi: 10.1016/j.schres.2009.07.021. PMID: 19713080, PMCID: PMC2763416.

42) Suganthy J, Raghuram L, Antonisamy B, Vettivel S, Madhavi C, Koshi R. Gender-and age-related differences in the morphology of the corpus callosum. Clin Anat. 2003; 16(5): 396-403. doi: 10.1002/ca.10161. PMID: 12903061.

43) Mourgela S, Anagnostopoulou S, Sakellaropoulos A, Gouliamos A. An MRI study of sex-and age-related differences in the dimensions of the corpus callosum and brain. Neuroanatomy. 2007; 6(1): 63-5.

44) Driesen NR, Raz N. The influence of sex, age, and handedness on corpus callosum morphology: a metaanalysis. Psychobiology. 1995; 23(3): 240-7.

45) Jancke L, Staiger JF, Schlaug G, Huang Y, Steinmetz H. The relationship between corpus callosum size and forebrain volume. Cereb Cortex. 1997; 7(1): 48-56. doi: 10.1093/cercor/7.1.48. PMID: 9023431.

46) Takeda S, Hirashima Y, Ikeda H, Yamamoto H, Sugino M, Endo S. Determination of indices of the corpus callosum associated with normal aging in Japanese individuals. Neuroradiol. 2003; 45(8): 513-8. doi: 10.1007/s00234-003-1019-8. PMID: 12879325.

47) Murphy DG, Decarli C, McIntosh AR, Daly E, Mentis MJ, Pietrini P, et al. Sex diffrences in human brain morphometry and metabulism: an in vivo quantitative magnetic resonance imaging and positron emission tomography study on the effect of aging. Arch Gen psychitry. 1996; 53(7): 585-94. doi: 10.1001/archpsyc.1996.01830070031007. PMID: 8660125.

48) Meng Y, Zhang X. Transcallosal Connectivity Changes from Infancy to Late Adulthood: An Ex-vivo Diffusion Spectrum Imaging Study of Macaque Brains. Brain Connect. 2015; 5(3): 147-55. doi: 10.1089/brain.2014.0285. PMID: 25389564, PMCID: PMC4394181.

49) Smith k, Kubiki m, Donnell LO, Westin CF, Niznikiewicz M, McCarley R, et al. Automatic cluster analysis of corpus callosum subdivisions in schizophrenia: A diffusion tensor imaging study. schizophrenia research. 2006; 94.

50) Awad IA, Spetzler RF, Hodak JA, Awad CA, Carey R. Incidental subcortical lesions identified on magnetic resononce imaging in the elderly. Correlation with age and cerebrovascular factors. Stroke. 1986; 17(6): 1084-9. PMID: 3810705.

51) Downhill JE Jr, Buchsbaum MS, Wei T, Spiegel-Cohen J, Hazlett EA, Haznedar MM, et al. Shape and size of the corpus callosum in schizophrenia and schizotypal personality disorder. Schizophr Res. 2000; 42(3): 193-208. PMID: 10785578. 